\title{
India's initiatives on Improving Energy Efficiency in Aluminium Industries
}

\author{
Piyush Verma $^{1}$, Alka Verma ${ }^{2}$, Anupam Agnihotri ${ }^{3}$
}

${ }^{1}$ Project Engineer, Bureau of Energy Efficiency, New Delhi, India

${ }^{2}$ Project Engineer, Energy Efficiency Services Limited, New Delhi, India

${ }^{3}$ Director, JawaharLal Nehru Aluminium Research Development \& Design Centre, Nagpur, India

\begin{abstract}
India is an important player in the aluminium, especially because of its abundant bauxite reserves and low-cost skilled manpower. The sector has a significant importance in the growth of Indian economy since the aluminium consumption follows GDP growth curve. Indian aluminium sector is observed as one of the energy intensive sectors with ample scope for improvements in energy efficiency as compared to world standards. The aluminium industries are upgrading themselves by adapting state-of-art technologies, which are more energyefficient and sustainable in a highly competitive market. These initiatives are further accelerated and motivated by an innovative incentivization scheme (called Perform, Achieve and Trade) of Govt. of India. Currently, the first phase (2012-15) is under implementation, and an unexpected movement towards energy efficiency is envisaged as a result that will ultimately lead towards production of low carbon aluminium for the society.
\end{abstract}

Key words: Industries, Aluminium, PAT, $\mathrm{CO}_{2}$ emission, sustainability

\section{INTRODUCTION}

India is the fifth largest producer of bauxite, accounting for $7.4 \%$ of global production in 2012 and the fifth largest producer of alumina. With a $3 \%$ share of global production of primary aluminium, India is among the top ten producers. The $90 \%$ increase in primary production since 2000 was mostly driven by demand for aluminium products arising from the aluminium used in transportation, building and electrical segments. With a dramatic increase in the production, the biggest challenge for the aluminium industries is to survive in a highly competitive market in a sustainable and cost-effective manner. 


\section{PAT SCHEME AND AlUMINIUM SECTOR}

The Ministry of Power, Government of India has notified industrial units and other establishments consuming energy more than the threshold in 9 industrial sectors namely Thermal Power Plants, Fertilizer, Cement, Pulp and Paper, Textiles, Chlor-Alkali, Iron \& Steel, Aluminium and Railways in March, 2007 as Designated Consumers (DCs). The Ministry of Power's notification issued on 2nd March 2007 under section 14 (e) of the Energy Conservation Act 2001 defines the threshold limit for aluminium industries to become a designated consumer. The threshold limit, as well as the identified number of designated consumers from different states, i.e.Odisha, Karnataka, Jharkhand, Chhattisgarh, Maharashtra and Uttar Pradesh is shown in Table 1.

Table 1: Minimum annual energy consumption and estimated number of DCs

\begin{tabular}{|l|l|l|}
\hline Sector & $\begin{array}{l}\text { Minimum annual energy } \\
\text { consumption } \\
\text { (tons of oil equivalent) }\end{array}$ & Number of Designated Consumers \\
\hline Aluminium & 7500 & $\begin{array}{l}10 \text { (Odisha-5, Karnataka-1, Jharkhand-1, } \\
\text { Chhatisgarh-1, Maharashtra-1, Uttar Pradesh-1) }\end{array}$ \\
\hline
\end{tabular}

The aluminium sector under the PAT scheme has been categorized into four sub-sectors based on their operations as shown in Figure 1:

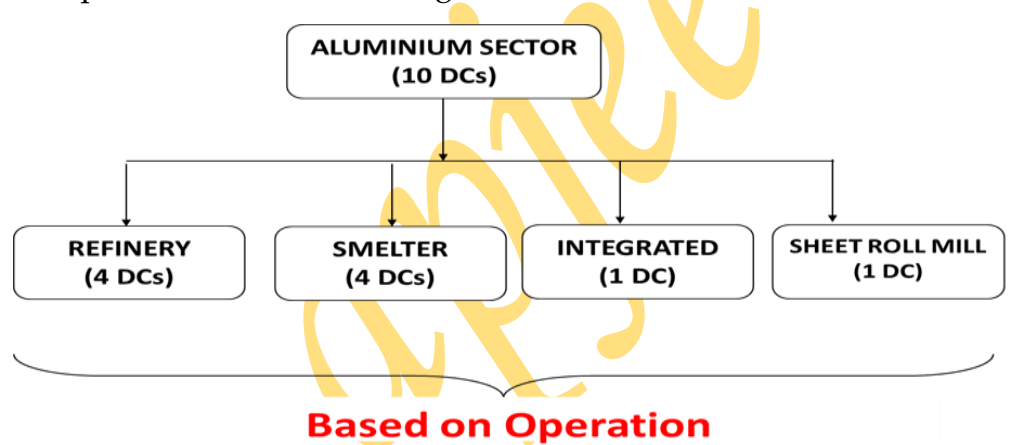

Figure 1. Subsectors under Aluminium sector

The processes of each sub-sector are defined as:

Refinery: Extracting alumina from a base material called bauxite.

Smelter: Converting alumina in to aluminium

Integrated: Where both processes (Refinery and Smelter) are available

Sheet Roll Mill: Producing end-use products i.e. aluminium rolled products

The products for each sub-sector have been defined for gate to gate calculation of specific energy consumption. The final products which have been considered for estimation of their baseline specific energy consumption are shown in Table 2:

Table 2. Final Products of different sub-sectors

\begin{tabular}{|c|c|}
\hline Sub-sector & Product \\
\hline Refinery & Calcined Alumina \\
\hline Smelter & Molten Aluminium \\
\hline Integrated & Molten Aluminium \\
\hline Sheet Roll mill & Molten Aluminium \\
\hline
\end{tabular}


The total reported energy consumption of these designated consumers is about 7.71 million ton of oil equivalent that is around $4.67 \%$ of total consumption of industries covered under PAT scheme.

\section{Estimation OF BASELINE AND TARget SETting}

The target setting for industries under the PAT scheme was a challenging process because of the wide bandwidth of specific energy consumption (SEC) in each of the industrial sectors. Although the wide bandwidth of SEC within an industrial sector is indicative of the large energy-savings potential in that sector but the challenging thing was to assign the energy saving targets to the individual industries as there was a wide variation amongst the plants because of their varying vintage, production capacity, raw material quality, and product-mix. The SEC bandwidth of the aluminium sector is shown in Table 3 where the SEC in most in-efficient plant was 35 times higher than the most efficient plant.

Table 3.SEC Bandwidth of Aluminium Sector

\begin{tabular}{|c|c|c|c|c|}
\hline \multicolumn{2}{|c|}{ Bandwidth of Sector } & \multicolumn{2}{|c|}{ Bandwidth Index } & \multirow{2}{*}{$\begin{array}{c}\text { Energy Savings } \\
\text { toe }\end{array}$} \\
\hline Min & Max & Min & Max & \\
\hline toe/t & toe/t & & & \\
\hline 0.183 & 6.405 & 1.00 & 35.00 & 0.456 \\
\hline
\end{tabular}

Such wide variation also makes it difficult to specify a single benchmark SEC for the sector as a whole: older plants will find the benchmark impossibly high if it is set at the level of newer plants; newer plants will find it trivial if it is set at the level of older plants. The broad bandwidth of SEC within a sector and the inability of all plants to achieve a sectoral benchmark SEC suggest that SEC improvement norms need to be set for individual plants. These SEC improvement targets can be based on the trend of energy consumption and energy-savings potential of the plants. In general, higher the energy efficiency (or, the lower SEC), indicates the lower energy-savings potential. Thus, it is evident that it is not feasible to define a single norm/standard unless there is significant homogeneity amongst units in a sector. Therefore, the energy efficiency improvement targets fixed are "unitspecific". Each industry under the sector has mandated to reduce its SEC by a certain value, based on its current SEC (or baseline SEC) within the sectoral bandwidth. The following target setting methodologies have been adopted in the aluminium sector:

- Sectoral target is allocated based on a pro-rate basis of total energy consumption in the aluminum sector among all the eight sectors covered under PAT scheme.

- Sub-sectoral target is allocated based on a pro-rata basis of total energy consumption in the sub-sector among the total aluminum sector.

- The designated consumer level target is allocated based on a statistical analysis derived from "Relative SEC" concept. This approach was applicable to all the designated consumers of a sub-sector only.

The baseline and target SEC for all the sub-sectors of aluminium sector has been shown in Figure 3: 


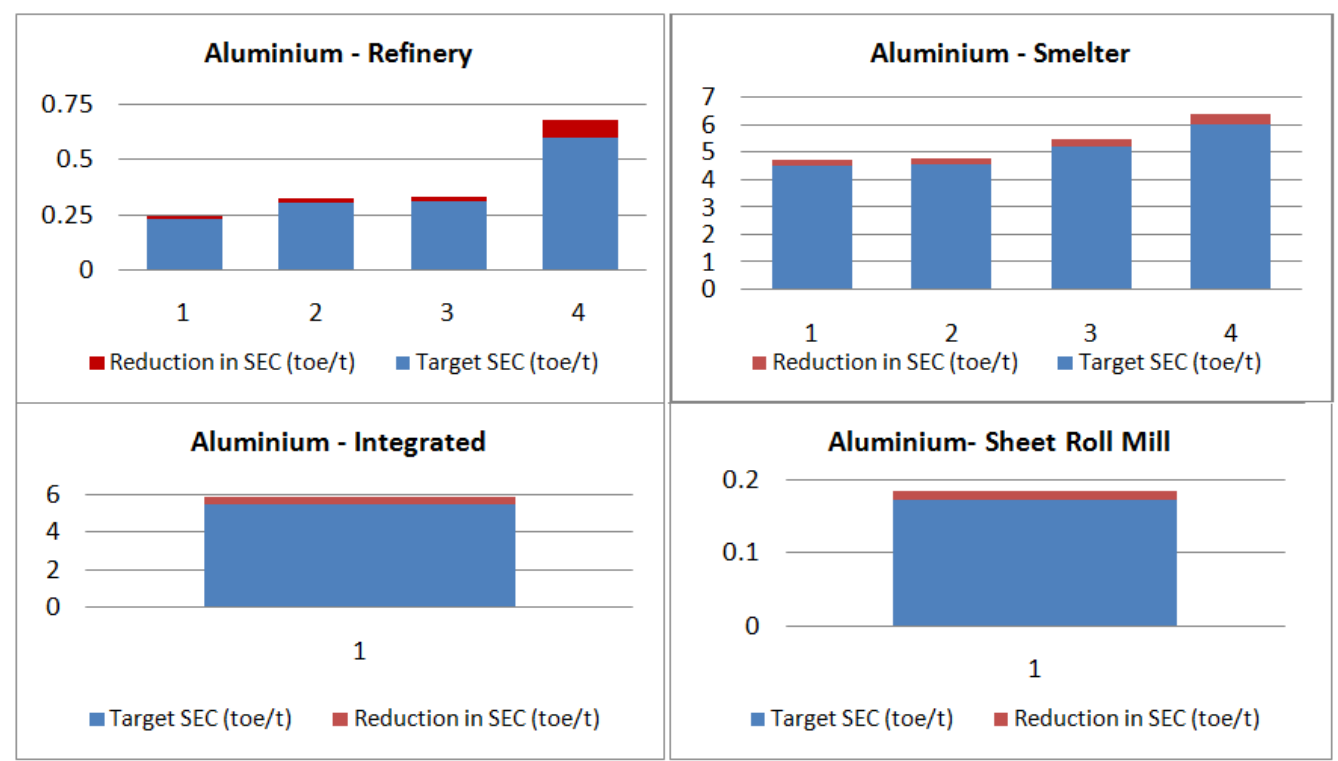

Figure 3.Baseline and Target SEC

The apportionment of baseline energy consumption as well as target energy saving of all these four sub-sectors is shown in Table 4. It is estimated that by the end of the first PAT cycle, the energy savings of 0.456 million ton of oil equivalent /year would be achieved, which will be around $7 \%$ of total national energy saving targets assessed under PAT scheme.

Table 4.Apportionment of sub-sectoral energy consumption and target

\begin{tabular}{|l|c|c|c|}
\hline \multirow{2}{*}{ Sub-Sector } & Avg. Energy Cons & & Target(Saving) \\
\cline { 2 - 4 } & Million ton of oil equivalent & $\mathbf{\%}$ & Million ton of oil equivalent \\
\hline Refinery & 0.917 & 11.89 & 0.054 \\
\hline Smelter & 4.505 & 58.45 & 0.266 \\
\hline Integrated & 2.277 & 29.54 & 0.134 \\
\hline Sheet-Roll Mill & 0.010 & 0.13 & 0.001 \\
\hline TOTAL & 7.71 & 100.00 & 0.456 \\
\hline
\end{tabular}

\section{ESTIMATION OF CO2 EMISSIONS REDUCTION}

The calculation of carbon-di-oxide emission reduction is based on the apportionment of the total energy savings to the fuels used by the individual designated consumers of the industrial sector. The apportionment of fuel savings is assumed same as the apportionment to the fuel consumption during the baseline period. The emission reductions for each designated consumer have been calculated and by adding the emissions of individual DCs the sectoral emissions have been estimated.

\section{FORMULA FOR CALCULATIONS}

For calculation of $\mathrm{CO}_{2}$ emission reduction, a very simple formula has been used in this paper. The amount of energy saved by reducing the usage of the fuel is multiplied by the emission factor of that same fuel gives the amount of $\mathrm{CO} 2$ emission reduction. The formula is as follows:

$\mathrm{CO} 2$ emission reduced (tons $\mathrm{CO} 2)=$ Avoided electricity purchase $(\mathrm{Kwh})^{*}$ Grid Emission factor (tons $\mathrm{CO} 2 / \mathrm{kwh}$ ) 


\section{METHOdOLOGY ADOPTED FOR CALCULATIONS}

The data has been decoded from the Energy Consumption Return Format submitted by the individual DCs which is coded into an excel based calculator that was designed for the calculation of the carbon emissions reductions. One of the important objective of feeding the data into the calculator is to determine the baseline energy profile of the individual DCs by which the target energy saving is divided according to the percentage of individual energy sources during the baseline period. Finally, the emissions factor of different fuel is multiplied by the fuels saved (amount of fuel saved $(\mathrm{kCal}){ }^{*}$ emission factor) gives the value of the emission reductions. The general steps for calculating the emissions are shown in Fig. 4.

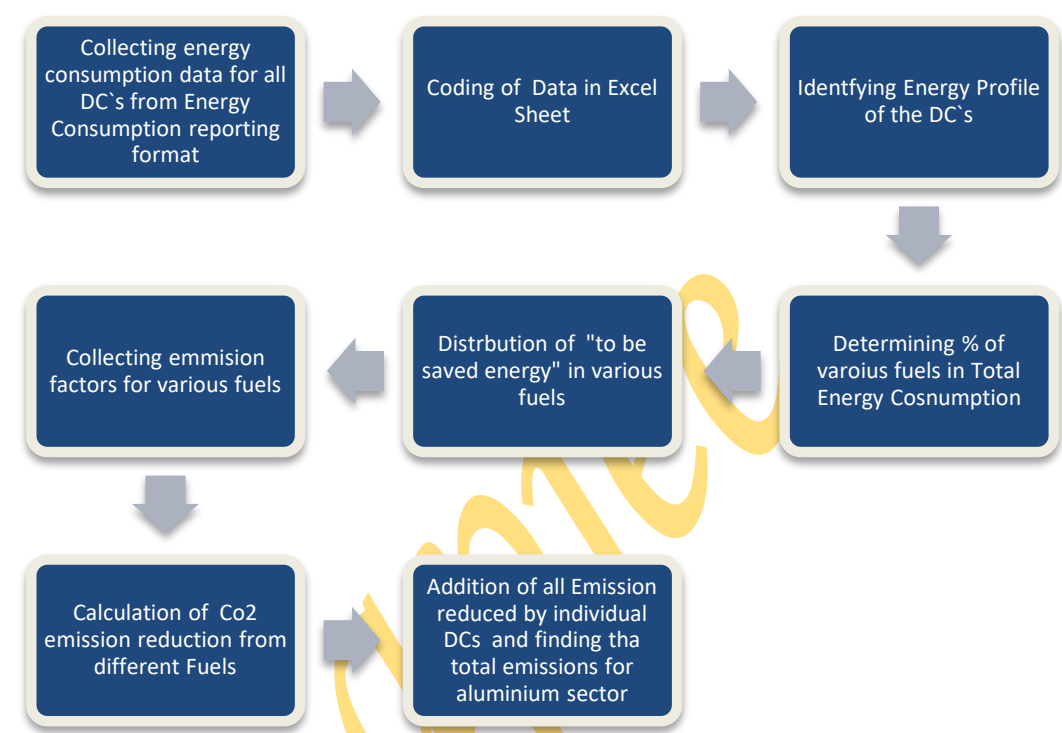

Figure 4. Methodology for emission reductions under PAT Scheme

\section{ASSUMPTIONS}

The following assumptions have been taken for calculation of carbon-di-oxide emissions:

- $\quad$ Every Industry meet the specified target under PAT $1^{\text {st }}$ Cycle

- $\quad$ The specified target will be reduced according to the current energy profile of the industry.

- $\quad$ The emission factors for liquid fuels like LSHS \& HSHS are assumed to be same.

- Various fuels like hydrogen, biomass, and MLSS pith are not included in calculating the emission reduction (as they are not included under PAT).

\section{CURRENT ENERGY PROFILE OF ALUMINIUM INDUSTRIES}

The total consumption of aluminium sector has been distributed in percentage of different fuels and it is found that the majority of energy consumption among the DCs in aluminium sector is of solid fuel consumption i.e. coal (Imported \& Indian). 


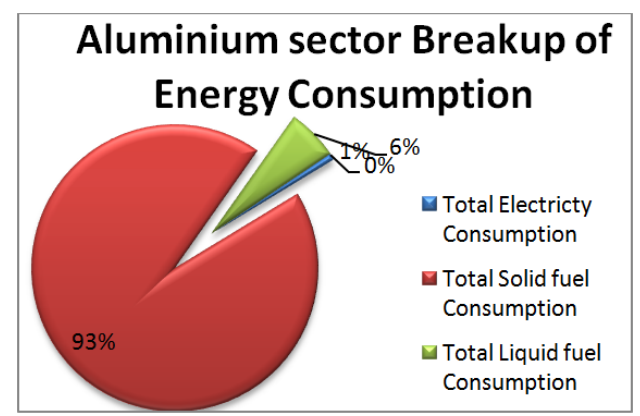

Figure 5. Breakup of energy consumption in the aluminum sector

Hence, it is clear that there is a wide scope of reducing the carbon-di-oxide emissions through enhancing efficiency of solid fuel consumptions in this sector.

\section{$\mathrm{CO}_{2}$ EMISSIONS SAVINGS (ALUMINIUM SECTOR)}

The total estimated $\mathrm{CO}_{2}$ reduction from the aluminium sector is given below:

Table 5: Emission savings Breakup

\begin{tabular}{|c|l|l|}
\hline S. No. & Energy Source & $\begin{array}{l}\text { Tones of } \mathrm{CO}_{2} \text { emission } \\
\text { reduction/savings }\end{array}$ \\
\hline 1. & Electricity & 122203.6504 \\
\hline 2. & Solid Fuels & 1485498.859 \\
\hline 3. & Liquid Fuels & 172366.0431 \\
\hline 4. & Gaseous Fuels & 10.58116212 \\
\hline & Total reduction from all DCs of the aluminium sector & 1780079.134 \\
\hline
\end{tabular}

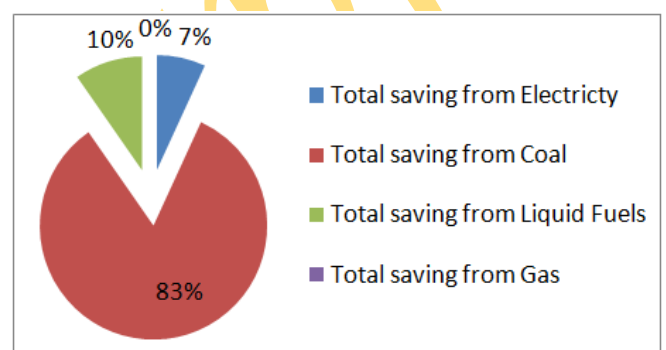

Figure 6.Estimated Savings/reduction of $\mathrm{CO} 2$ (in percentage)

\section{CRI (CARBon Reduction InTENSITY)}

For the analysis of $\mathrm{CO}_{2}$ emission reduction from PAT scheme, a new variable called Carbon reduction Intensity (CrI) has been defined. Carbon reduction intensity represents the value of tones of emissions reduction to the per unit of energy saving. The sector having the highest value of $\mathrm{CrI}$ has the highest potential of emission reduction. The $\mathrm{CrI}$ would be approximately same for all the DCs of aluminium sector because of the similar energy profile of individual industries.

The CrI of the aluminium sector is expected to have high value, because of the dependency of aluminium sector on the Fossils fuels for meeting their energy needs. The CrI of Aluminium Sector has been estimated as 3.91 tones/toe. It means for every toe of target savings, 3.91 tones of $\mathrm{CO}_{2}$ will be saved. 
Table 6: CrI of Aluminium sector

\begin{tabular}{|l|l|l|l|}
\hline S. No. & Particulars & Values & Units \\
\hline & Total Target Energy Savings for the Sector & 454997 & toe \\
\hline & Total emission savings for the Sector & 178079.134 & Tonnes \\
\hline & CrI (Carbon reduction Intensity) & 3.91 & Tonnes/mtoe \\
\hline
\end{tabular}

CrI of individual industries under aluminium sector has been shown in Fig. 7.

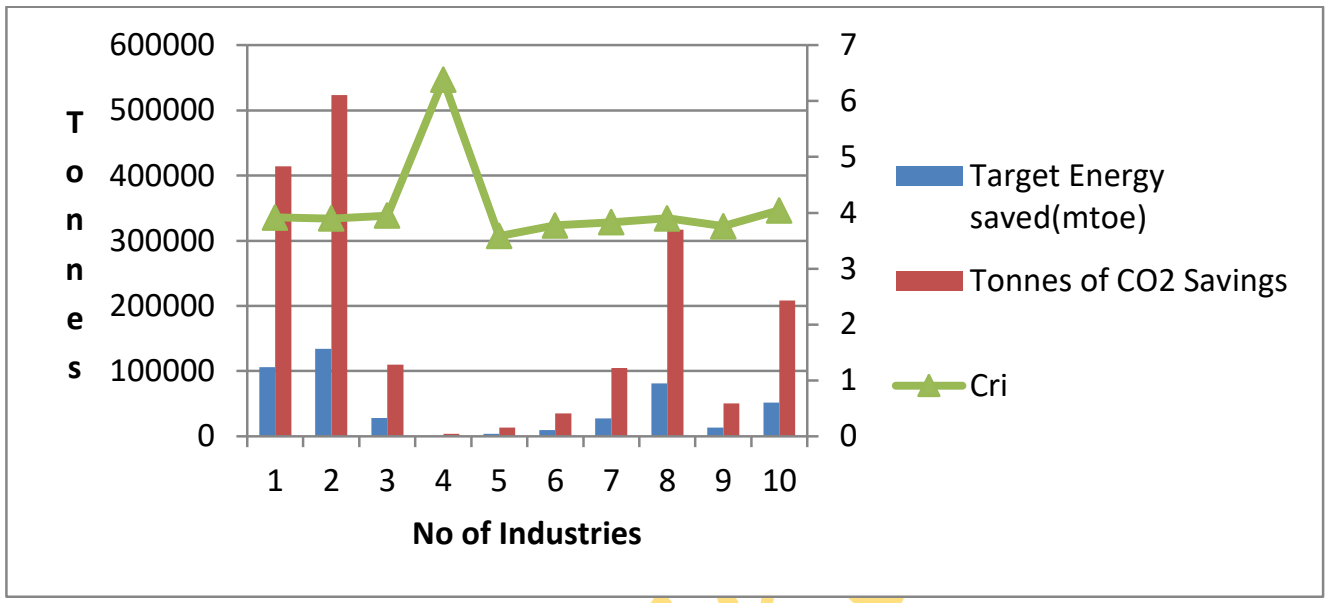

Figure 7.1CrI of Industries under Aluminium Sector

\section{CONCLUSION}

The aluminium industry is one of the major industry which helps in the economic development of countries like India at large. At the same time, it is also one of the energy intensive sectors among various industrial sectors in India. Major energy consumption in aluminium industries is in the form of electricity that is generated by a less-efficient coal fired captive power plants. All these results in high volume generation of $\mathrm{CO}_{2}$ including that of the aluminium smelting process. Therefore, there is an urgent need to re-focus on energy efficiency need for delivering sustainable aluminium in a longer term.

This paper has demonstrated the carbon emission reduction benefit of India's initiatives of considering aluminium industries under PAT scheme. It is envisaged that considering the deepening of the threshold limit of aluminium industries in further years will greatly enhance the demand of energy efficiency in this sector. The target setting process in the consecutive PAT cycles should be further stringent to narrow down the bandwidth of SECs of this sector at the international level.

\section{ACKNOWLEDGEMENTS}

The authors are thankful to Bureau of Energy Efficiency, Energy Efficiency Services Limited, Jawaharlal Nehru Aluminium Research Centre and other organizations who are directly and indirectly involved in conducting this study. The authors would also like to thank to Mr.Atik Shiekh, Intern at BEE for helping in the development of excel based carbon emission calculator for aluminium sector. 


\section{REFERENCES}

Ali, M., \& Alam, M. (2014). Study on MHD Boundary Layer Flow of Combined Heat and Mass Transfer over a Moving Inclined Plate in a Porous Medium with Suction and Viscous Dissipation in Presence of Hall Effect. Engineering International, 2(1), 43-63. Retrieved from http://i-scholar.in/index.php/ENIABC/article/view/54736

Ashim Chaudhary, Emissions from Electricity Generation, Central Institute of Mining \& Fuel Research.

CO2 Baseline Database For Indian Power Sector, User Guide-Version 6, Central Electricity Authority, Ministry of power.

Costache, M., \& Jagite, G. (2014). Global Strength Analysis in Head Waves, for an Offshore Support Vessel. Asian Journal Of Applied Science And Engineering, 3(8), 73-90. doi:10.15590/ajase/2014/v3i8/54486

Dr. Pradeep Dadhich, Second National Communication: Emissions from Residential and Commercial Sector. TERI, April 2010

Energy conservation Act, 2001, Ministry of Power (MoP), Government of India (Government of India).

Government of India Gazette Notification, S. O. 687 (E), $30^{\text {th }}$ March, 2012

Government of India Gazette Notification, S.O. 394 (E), 12 ${ }^{\text {th }}$ March, 2007

Hao NT and Jungkyu P. 2013. CRN Application to Predict the NOx Emissions for Industrial Combustion Chamber Asian Journal of Applied Science and Engineering, 2, 9-26.

Happy FA, Hossain MS and Rahman A. 2014. Pressure Data Analysis and Multilayer Modeling of a Gas-Condansate Reservoir Asia Pacific Journal of Energy and Environment, 1, 172-181.

Hoseinimotlagh, S., \& Jahedi, M. (2014). Determination of Energy Gain Time Dependent in D+T Mixture with Calculating Total Energy Deposited of Deuteron Beam in Hot Spot. Asia Pacific Journal Of Energy And Environment, 1(1), 07-21. doi:10.15590/apjee/2014/v1i1/53741

Hosseinimotlagh, S. (2014). Computation of Time Energy Gain in D-3He Mixture: Energy Deposited through Deuterium Ignition Beam. Asia Pacific Journal Of Energy And Environment, 1(2), 156172. doi:10.15590/apjee/2014/v1i2/53751

India: Greenhouse Gas Emissions 2007, Indian Network for Climate Change Assessment.

Islam MS and Mondal T. 2013. Potentiality of Biomass Energy for Electricity Generation in Bangladesh Asian Journal of Applied Science and Engineering, 2, 103-110.

Madani, S. (2014). Effect of Different Parameters on Solar Pond Performance. Asia Pacific Journal Of Energy And Environment, 1(1), 54-69. doi:10.15590/apjee/2014/v1i1/53746

Mahmud TA. 2012. A Survey on How Dynamically Changes Topology in Wireless Sensor Network ABC Journal of Advanced Research, 1, 28-34.

Nathalie Trudeau, Cecilia Tam, Dagmar Graczyk and Peter Taylor: Energy Transition for industry: India and the global context, International Energy Agency (IEA), 2011.

PAT Consultation Document 2010-11, Bureau of Energy Efficiency.

Sanjay Dube, RiteshAwashti, Vivek Dhariwal, A Discussion: India's Perform Achieve and Trade(PAT) Scheme. 